\title{
Effect of High Pressure on the Porcine Placenral Hydrolyzing Activity of Pepsin, Trypsin and Chymotrypsin
}

\author{
Ji-Yeon Chun, Yeon-Ji Jo, Sang-Gi Min, and Geun-Pyo Hong* \\ Department of Bioindustrial Technologies, Konkuk University, Seoul 143-701, Korea
}

\begin{abstract}
This study investigated the effects of protease treatments (trypsin, chymotrypsin, and pepsin) under various pressure levels (0.1-300 MPa) for the characteristics of porcine placenta hydrolysates. According to gel electrophoretic patterns, the trypsin showed the best placental hydrolyzing activity followed by chymotrypsin, regardless of the pressure levels. In particular, the peptide bands of tryptic-digested hydrolysate were not shown regardless of applied pressure levels. The peptide bands of hydrolysate treated chymotrypsin showed gradual decreases in molecular weights $\left(M_{\mathrm{w}}\right)$ with increasing pressure levels. However, the pepsin did not show any evidences of placental hydrolysis even though the pressure levels were increased to $300 \mathrm{MPa}$. The gel permeation chromatography (GPC) profiles showed that the trypsin and pepsin had better placental hydrolyzing activities under high pressure (particularly at $200 \mathrm{MPa}$ ), with lower $M_{\mathrm{w}}$ distributions of the hydrolysates. Pepsin also tend to lower the $M_{w}$ of peptides, while the major bands of hydrolysates being treated at $300 \mathrm{MPa}$ were observed at more than 7,000 Da. There were some differences in amino acid compositions of the hydrolysates, nevertheless, the peptides were mainly composed of glycine (Gly), alanine (Ala), hydroxyproline (Hyp) and proline (Pro). Consequently, the results indicate that high pressure could enhance the placental hydrolyzing activities of the selected proteases and the optimum pressure levels at which the maximum protease activity is around $200 \mathrm{MPa}$.
\end{abstract}

Key words: porcine placenta, high pressure, hydrolysates, protease, enzyme activity

\section{Introduction}

Although collagen is the most abundant protein source which can be obtained from various animal wastes or byproducts, it has not been attracted much attention as a nutritional source due to a lack of some essential amino acids such as tryptophan (Szpak, 2011). Collagen has a molecular weight $\left(M_{\mathrm{w}}\right)$ of about $300 \mathrm{kDa}$ and composed of double $\alpha$-chains $(\sim 100 \mathrm{kDa})$ and $\beta$-chain $(\sim 200 \mathrm{kDa})$ structured by triple-helix (Furthmayr and Timpl, 1971). Recently, interests in collagen hydrolysates are greatly grown as a food, cosmetic or pharmaceutical ingredient since various bioactivities and functionalities of the hydrolysateshave been identified (Giménez et al., 2009; Iwai et al., 2005). It has been reported that collagen hydrolysates show different bioactivity depending on the molecular weights and amino acid sequence. For instant, antioxidant activity was identified in the collagen hydrolysates which

*Corresponding author: Geun-Pyo Hong, Department of Bioindustrial Technologies, Konkuk University, Seoul 143-701, Korea. Tel: 82-2-450-3674, Fax: 82-2-455-1044, E-mail: genpro@konkuk.ac.kr were composed of 10-15 amino acids while antihypertensive (ACE inhibitory) activity were shown in the peptides consisted of 2-4 amino acids (Gómez-Guillén et al., 2011).

Commercial collagen hydrolysatesare produced mainly by acid treatments or by enzymatic digestion. In particular, acid treatment (normally $\mathrm{HCl}$ ) a thigh temperature has been a standard way to produce collagen hydrolysates within a few hours (Tsugita and Sheffler, 1982), however, it also implies a generation of waste water and a requirement of neutralization/desalting processes. In more recent, subcritical water processing has been introduced as a novel collagen hydrolysis technology (Lee et al., 2013). Upon elaborated pressure and temperature (subcritical region), collagen converts into gelatin and undergoes partial or complete hydrolysis depending on the subcritical conditions such as temperature. Our previous study indicated that subcritical water processing $\left(37.5 \mathrm{MPa}\right.$ and $\left.170^{\circ} \mathrm{C}\right)$ had a potential advantage to hydrolyze collagen within a few minutes (Lee et al., 2013). Disadvantage of subcritical hydrolysis of collagen was relatively high $M_{\mathrm{w}}(>5 \mathrm{kDa})$ of collagen hydrolysates.

The usage of proteases is an alternative of the second hydrolyze collagen. In spite of high cost of final products, 
enzymatic hydrolysis is a common method to produce high quality collagen peptides (Clemente, 2000). Various enzymes including trypsin, pepsin, chymotrypsin, alcalase as well as collagenase are involved in collagen hydrolysis. Intriguingly, hydrolysis activity of proteases has been reported to be enhanced under and/or after high pressure treatment (Northrop, 2002). It is likely that enhanced proteolysis activity of the enzymes provides various advantages in reducing the $M_{\mathrm{w}}$ of final product with reduced cost. Therefore, this study was conducted to evaluate the effects of high pressure (0.1-300 MPa) on the collagenhydrolyzing activity of various proteases (pepsin, trypsin, and chymotrypsin).

\section{Materials and Methods}

\section{Materials}

Frozen porcine placenta was kindly donated by Samwoo Husbandry Co. (Korea). The frozen placenta was thawed in running water for $4 \mathrm{~h}$ and washed with water containing detergent to remove residual blood. The placenta was further washed with water several times and dewatering process was done by centrifugation at $\times 1,000$ $\mathrm{g}$ for $15 \mathrm{~min}$. Visual fat was completely trimmed off and the placenta was cut into about $5 \mathrm{~cm}$ in length. Aliquots of $1 \mathrm{~kg}$ placenta were vacuum-packaged using polyethylene pouch and frozen at $-50^{\circ} \mathrm{C}$ prior to use (within 2 mon). Pepsin (E.C. 3.4.23.1, from porcine gastric mucosa, 250 units/mg protein), trypsin (E.C. 3.4.21.4, from bovine pancrease, 10,000 BAEE (N-benzoyl-L-arginine ethyl ester) units/mg protein) and $\alpha$-chymotrypsin (E.C. 3.4. 21.1, from bovine pancrease type-II, 40 units/ $\mathrm{mg}$ protein) were purchased from Sigma-Aldrich Co. (USA). All che- micals used in this study were analytical grade.

\section{Treatment}

Frozen placenta was thawed at $4^{\circ} \mathrm{C}$ overnight. Moisture and crude protein contents of the placenta were determined respectively by $102^{\circ} \mathrm{C}$ air drying and by Kjeldahl $(\% \mathrm{~N} \times 6.25)$. The placenta was blended using a SMT homogenizer (SMT Co. Ltd., Japan) for $5 \mathrm{~min}$ and aliquot $50 \mathrm{~mL}$ was mixed with each protease (40 unit/mg of pepsin and chymotrypsin, 25.0 BAEE unit/mg of trypsin). High pressure was applied using a lab-assembled barostatic device. In brief, the device was composed of pressure generator, intensifier and pressure controller, and water was used for pressure-transmitting medium. Samples were pressurized at 100,200, and $300 \mathrm{MPa}$ for $5 \mathrm{~min}$ at ambient temperature. After depression, all samples were further incubated at $4^{\circ} \mathrm{C}$ for $2 \mathrm{~h}$ and the enzymes were inactivated by immersing the samples in $75^{\circ} \mathrm{C}$ water bath for $15 \mathrm{~min}$.

\section{Gel electrophoresis}

Samples were vigorously voltexed and diluted to final 4 $\mathrm{mg} / \mathrm{mL}$ protein concentration by adding adequate amount of distilled water. Sodium dodecyl sulfate-poly acrylamide gel electrophoresis (SDS-PAGE) was conducted using EzWay ${ }^{\mathrm{TM}}$ PAG $12 \%$ acrylamide gels (KOMA Biotech Inc., Korea) based on the method of Laemmli (1970). The sample dilutes were mixed with the same amount of KTG20 sample buffer (KOMA Biotech Inc., Korea) consisting of $10 \%$ glycerol, $2 \%$ SDS, $0.003 \%$ bromophenol blue, $5 \%$ $\beta$-mercaptoethanol and $63 \mathrm{mM}$ Tris ( $\mathrm{pH}$ 6.8). The mixture was boiled for $2 \mathrm{~min}$ and $20 \mu \mathrm{L}$ of sample mixture was loaded into the gel wells. Peptide separation was performed at a constant voltage of $140 \mathrm{~V}(\sim 1 \mathrm{~h})$.

\section{Gel permeation chromatography (GPC)}

Samples were centrifuged at $\times 10,000 \mathrm{~g}$ for $5 \mathrm{~min}$ and the molecular weight $\left(M_{\mathrm{w}}\right)$ of peptides in the supernatant was determined by GPC based on the method of Gu et al. (2011). A YL 9100 high performance liquid chromatography (HPLC) system (Younglin Instrument Co. Ltd., Korea) equipped with three Ultrahydrogel ${ }^{\mathrm{TM}} 120$ columns (7.8×3,000 mm, Waters, USA) was used for GPC analysis. The flow rate of mobile phase was $1 \mathrm{~mL} / \mathrm{min}$ using deionized/distilled water. The $M_{\mathrm{w}}$ distributions of the peptides were monitored using a YL 9100 refractive index detector (YL Instrument Co. Ltd., Korea) at $40^{\circ} \mathrm{C}$. A $M_{\mathrm{w}}$ standards kit (0.68-1,670 kDa, Polymer standards service, Germany) was used as standards.

\section{Amino acid composition}

Amino acid composition of the sample supernatant was determined using an Agilent HPLC 1200 system (Agilent Technologies Inc., USA) equipped with two detectors (a fluorescence detector and a UV detector) and a $\mathrm{C}_{18}$ column $(4.6 \times 150 \mathrm{~mm}, 5 \mu \mathrm{m}$ in diameter). The supernatant containing $3 \mathrm{mg}$ of total protein was added to $30 \mathrm{~mL}$ of $6 \mathrm{M}$ $\mathrm{HCl}$ and hydrolyzed at $130^{\circ} \mathrm{C}$ for $24 \mathrm{~h}$. After hydrolysis, the sample was diluted with distilled/deionized water up to total volume of $100 \mathrm{~mL}$, and then filtered using a DISMIC-13CP $0.45 \mu \mathrm{m}$ syringe filter (Advantec Co., Japan). Two mobile phases were applied, i.e., one was $20 \mathrm{mM}$ sodium phosphate buffer ( $\mathrm{pH} 7.8$ ) and the other was $45 \%$ (v/v) acetonitrile/45\% (v/v) methanol solution. The sam- 
ples were monitored at an emission wavelength of 450 $\mathrm{nm}$ and an excitation wavelength of $340 \mathrm{~nm}$ for the $o$ phthalaldehyde derivatives, and an emission wavelength of $305 \mathrm{~nm}$ and an excitation wavelength of $266 \mathrm{~nm}$ for the 9-fluorenylmethyl chloroformate derivatives at $40^{\circ} \mathrm{C}$ in the case of fluorescence detecting and an absorbance at $338 \mathrm{~nm}$ at $40^{\circ} \mathrm{C}$ in the case of UV detecting. An Agilent 5061-3330 (Agilent Technologies Inc., USA) was used as the standard.

\section{Statistical analysis}

Completely randomized design was adopted to evaluate the effect of pressure levels or types of enzyme. One-way analysis of variance (ANOVA) was conducted using a SAS statistical program (ver. 9.1) and the means were separated by Duncan's multiple range test when the main effect (pressure levels) was significant $(p<0.05)$.

\section{Results and Discussion}

\section{Gel electrophoresis}

The three selected proteases exhibited different hydrolyzing features based on peptide band patterns of placenta (Fig. 1). For pepsin treatments, high $M_{\mathrm{w}}$ bands were shown in the $M_{\mathrm{w}}$ range of $>55 \mathrm{kDa}$, reflecting that pepsin had a poor placental hydrolysis activity. Contrary to literature which postulates proteolysis activity of pepsin (Skierka and Safdowska, 2007), poor hydrolysis in the present study would be due to type of substrate (mainly collagen) and environmental conditions $(\mathrm{pH})$. Pepsin is reported to cleave peptide bonds between hydrophobic and aromatic amino acids (Dunn, 2001). Because collagen rarely contains the aromatic amino acids such as tyrosine, tryptophan and phenylalanine (Dunn, 2001; Nelson and Cox, 2008), placenta suspension is not a good substrate for the peptic-digestion. In addition, the optimum reaction of

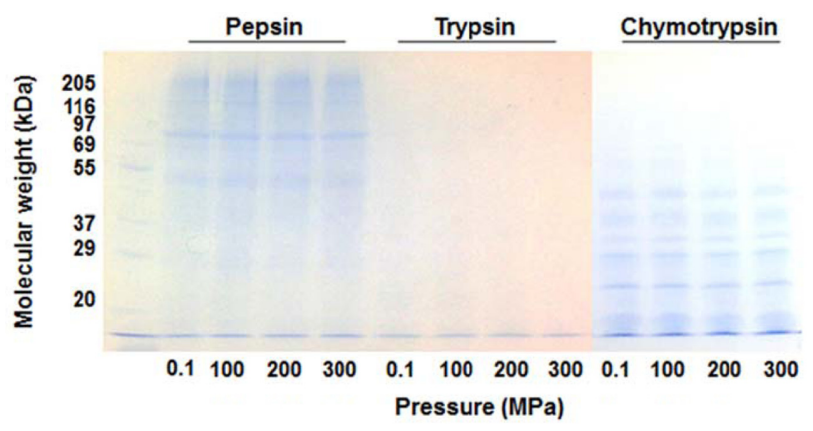

Fig. 1. SDS-PAGE pattern of porcine placenta treated with proteases and pressurized for $5 \mathrm{~min}$ after incubation at $4^{\circ} \mathrm{C}$ for $2 \mathrm{~h}$. pepsin is occurred at around $\mathrm{pH} 2$. At higher than neutral region, pepsin is inactivatedand irreversibly denatured (Johnston et al., 2001). The placenta suspension had a pH about 6.3 which was too high for pepsin to hydrolyze the substrates as reported by Lee et al. (2013). These factors would also affect the activity of pepsin under high pressure, being shown no visual changes in peptide band patterns.

For trypsin treatments, no bands were detected at atmospheric condition, indicating that trypsin had a potential to hydrolyze collagen. High $M_{\mathrm{w}}$ peptides were completely hydrolyzed which attributed no visual bands in SDS-PAGE gel, and the tryptic-digested hydrolysates had $M_{\mathrm{w}}$ below $20 \mathrm{kDa}$. Therefore, the effect of high pressure on the tryptic-digestion of placenta was not identical in SDS-PAGE.

The chymotrypsin-treated placenta showed different band intensities depending on applied pressure levels. All bands of placental hydrolysates were in the range of $<40$ $\mathrm{kDa}$ with more than 6 peptide bands. With increasing pressure, the bands of $30-40 \mathrm{kDa}$ lost their intensities probably as a result of further hydrolysis, hencehigh pressure seemed to enhance the enzyme activity for placental hydrolysis. Meanwhile, the bands below $29 \mathrm{kDa}$ were not affected by pressure levels.

Based on the results from gel electrophoresis, it could be concluded that trypsin had the best placental hydrolysis ability followed by chymotrypsin and pepsin. However, it should be noted that the trypsin concentration (BAEE units/mg protein) applied in this study could not compensate for that of chymotrypsin (unit/mg). On the other hand, trypsin in the present study was used after high dilution $(\times 400)$. Therefore the usage of trypsin for collagen hydrolysis had advantages in product cost and hydrolyzing efficiency comparing to chymotrypsin and pepsin.

\section{$M_{\mathrm{w}}$ distribution}

Because gel electrophoresis did not provide information regarding the $M_{\mathrm{w}}$ distributions of placenta hydrolysates, supernatant of the enzyme-treated samples were analyzed by GPC (Fig. 2). Despite that pepsin exhibited poor placental hydrolysis ability in gel electrophoresis, the limited amounts of peptides produced by this enzymatic digestion were mainly separated by two groups, one group had a $M_{\mathrm{w}}$ higher than $20 \mathrm{kDa}$ and the other group of which $M_{\mathrm{w}}$ was lower than $434 \mathrm{Da}$. Considering a repetitive primary structure of collagen, the former would be limited hydrolysates from collagen polymer while the latter was thought to be hydrolysates cleaved from $\mathrm{C}$ and/ 


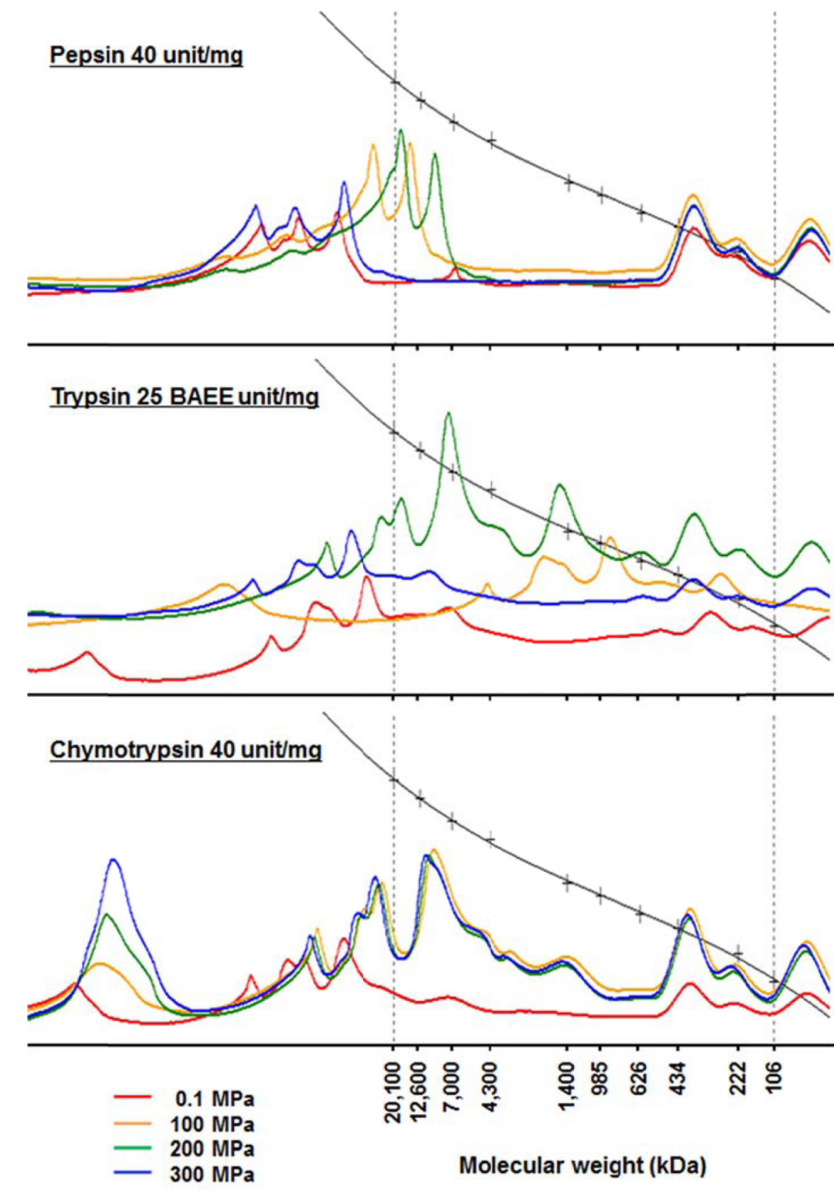

Fig. 2. Gel permeation chromatograph of porcine placenta treated with proteases and pressurized for $5 \mathrm{~min}$ after incubation at $4^{\circ} \mathrm{C}$ for $2 \mathrm{~h}$.

or N-terminal of collagen which was composed of 2-3 amino acids (Lee et al., 2013). With increasing pressure levels, the low $M_{\mathrm{w}}$ group was not affected irrespective of pressure levels while the high $M_{\mathrm{w}}$ peaks were shifted toward lower $M_{\mathrm{w}}$ range, indicating that hydrolysis activity of pepsin was enhanced after pressurization. The shift of high $M_{\mathrm{w}}$ peaks was preceded when the enzyme/placenta mixture was pressurized at $200 \mathrm{MPa}$. In particular, all peptides belonging to high $M_{\mathrm{w}}$ group were observed within 20 $\mathrm{kDa}$ region, indicating the optimum pressure level for the maximum enhancement of peptic-digestion. The pressureinduced activity enhancement of pepsin was also reported when the substrate was soybean (Peñas et al., 2006) or milk proteins (Chicón et al., 2008). Alternately, further increase in pressure $(300 \mathrm{MPa})$ resulted in higher $M_{\mathrm{w}}$ peaks than control $(0.1 \mathrm{MPa})$. The result was not in agreement with Chicón et al. (2008) where the authors demonstrated that pepsin-catalyzed $\beta$-lactoglobulin hydrolysis was intense with increasing pressure levels up to $400 \mathrm{MPa}$. Different substrate $\mathrm{pH}$ would result in different structural tolerance of pepsin over pressure.

The patterns in tryptic-digestion of placenta were also similar to those of pepsin. At atmospheric condition, hydrolysates of trypsin treatment had broad ranges of $M_{\mathrm{w}}$ peaks. With increasing pressure (100 MPa), all $M_{\mathrm{w}}$ peaks shifted greatly to lower $M_{\mathrm{w}}$ region, and the main peaks were detected at $1-5 \mathrm{kDa}$. At $200 \mathrm{MPa}$, the peaks were detected at lower $M_{\mathrm{w}}$ ranges comparing to those of control $(0.1 \mathrm{MPa})$, however, the placental hydrolysis activity was lesser than that treated at $100 \mathrm{MPa}$. The decrease in tryptic-digestion activity was also shown when the hydrolyzing reactant was subjected at $300 \mathrm{MPa}$ at which the $M_{\mathrm{w}}$ peaks were displayed at slightly higher ranges than those of control. Consequently, the optimum pressure level for tryptic-digestion was found at $100 \mathrm{MPa}$. Peñas et al. (2004) also noted similar results using soybean protein and concluded that pressure-induced aggregation of substrate diminished the hydrolysis activity of trypsin. In the current study, however, it was hardly expected that high pressure affected the placental collagen, because high pressure was reported not to attribute the collagen structure (Suzuki et al., 1993). It was recognized that transient pressure of trypsin between native and denatured states was $6.5 \mathrm{kbar}(650 \mathrm{MPa})$, while it depending on the concentration of proteins, ratio of enzyme to substrate and temperature (Ruan et al., 1997). In the mixed conditions with substrate, there would be an interaction between hydrolysates and enzyme under high pressure and resulted less activity at higher than $200 \mathrm{MPa}$ (Peñas et al., 2004).

The placental hydrolysates obtained by chymotrypsin showed some unique pattern under high pressure. Increasing pressure up to $100 \mathrm{MPa}$ resulted better hydrolysis of placenta as shown in lower $M_{\mathrm{w}}$ peaks than those obtained by control. However, no peak changes were shown with increasing pressure $(>200 \mathrm{MPa})$. The only attribute of chymotryptic digestion was an increase of the highet $M_{\mathrm{w}}$ peak dimension. Partial collagen peptides appeared to be fractionated and likely accumulated in the suspension.

\section{Amino acid compositions}

Comparing the amino acid compositions of raw placenta, all digested hydrolysates showed similar pattern of changes after enzymatic hydrolysis (Fig. 3). The enzymatic hydrolysis did not affect the contents of His and Met. Meanwhile significant increases in Gly, Ala, Lys, Hyp and Pro were observed with decreasing the other amino acid compositions $(p<0.05)$. The amino acids of placental hydrolysates were also in agreement with our previous study (Lee et al., 2013). For peptic and chymotryptic-digestions, 

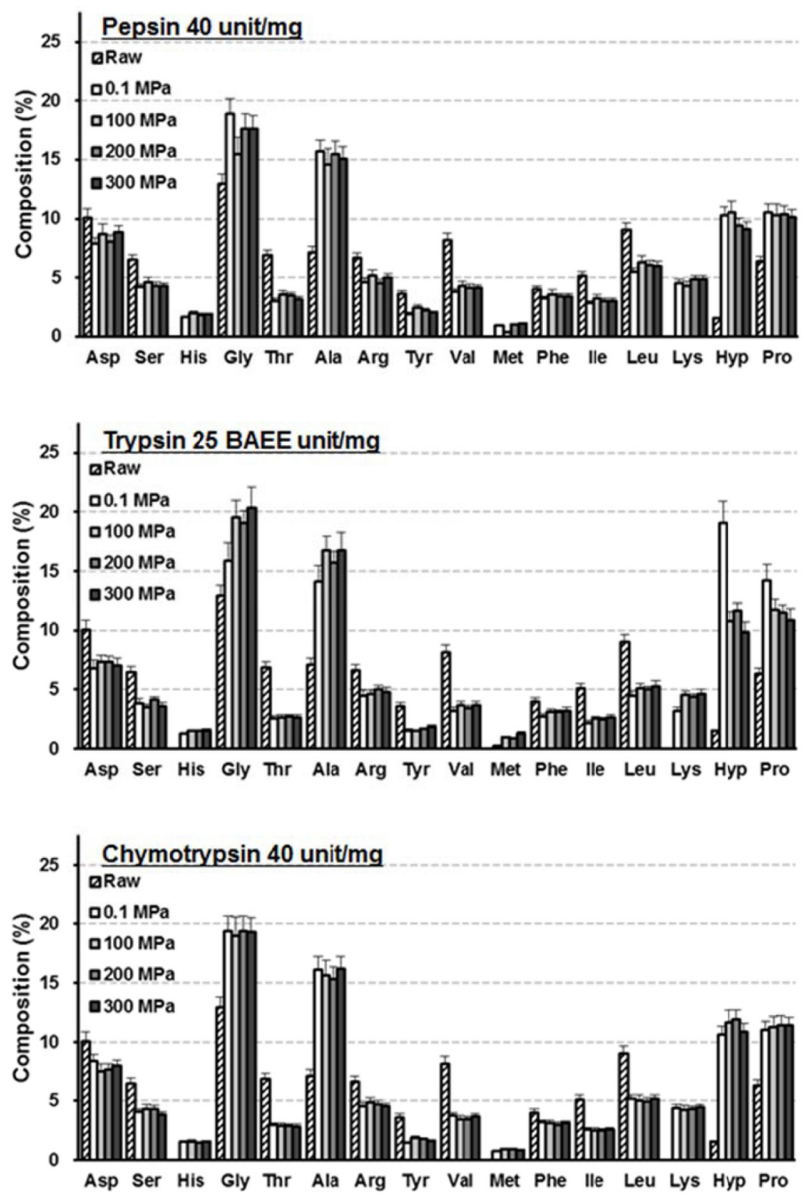

Fig. 3. Amino acid composition of porcine placenta treated with proteases and pressurized for 5 min after incubation at $4^{\circ} \mathrm{C}$ for $2 \mathrm{~h}$. Vertical bars represent standard deviations $(n=3)$.

changes in amino acid compositions with pressure level were not significant, though Gly in peptic-digested placenta hydrolysate was lowest at $100 \mathrm{MPa}$ treatment $(p<$ 0.05 ). Meanwhile, tryptic-digested placenta hydrolysates showed clear changes in amino acid contents by pressurization. In particular, Gly and Ala contents of trypticdigested hydrolystae increased at $100 \mathrm{MPa}$. The Ala content did not differ among pressure treatments while Gly content was further increased with increasing pressure up to $200 \mathrm{MPa}(p<0.05)$ thereafter no differences in Gly contents were observed. In addition, Hyp and Pro contents decreased at $100 \mathrm{MPa}(p<0.05)$ and tended to decrease with increasing pressure levels, reflecting pressure-dependent peptide clavage of trypsin. It is reported that trypsin cleaves the carboxyl residues of Lys or Arg. However, this enzyme does not attack the same residues when it is followed by Pro (Rodriguez et al., 2008). Considering that the low $M_{\mathrm{w}}$ peptides of tryptic-digestion was found at 100 MPa treatment based on GPC, the relationship between pressure levels and amino acid compositions of trypticdigested placenta was not clear in the present study, which warranted further exploration.

\section{Conclusion}

This study demonstrated the enhancement of hydrolyzing activities of three selected proteases under high pressure. Trypsin revealed a potential protease to hydrolyze animal by-product collagen effectively. Although, it was obscure whether an interaction between enzyme and substrate was occurred under pressure or structural modification of the enzymes caused the enhancement of placental hydrolyzing activity, 100-200 MPa of pressurization was favorable to improve the proteolytic activity. Consequently, the results indicated that pressurization had a potential advantage in enzymatic-collagen hydrolysis.

\section{Acknowledgements}

Financial support for this study was obtained from the Korean Institute of Planning and Evaluation for Technology in Food, Agriculture, Forest, and Fisheries, Korea (iPET Project No. 311029-3).

\section{References}

1. Chicón, R., López-Fandiño, R., Alonso, E., and Belloque, J. (2008) Proteolytic pattern, antigenicity, and serum immunoglobin $\mathrm{E}$ binding of $\beta$-lactoglobulin hydrolysates obtained by pepsin and high-pressure treatments. J. Dairy Sci. 91, 928938.

2. Clemente, A. (2000) Enzymatic protein hydrolysates in human nutrition. Trend. Food Sci. Technol. 11, 254-262.

3. Dunn, B. M. (2001) Overview of pepsin-like aspartic peptidases. Curr. Prot. Protein Sci. unit 21.3, 1-6.

4. Furthmayr, H. and Timpl, R. (1971) Characterization of collagen peptides by sodium dodecylsulfate-polyacrylamide electrophoresis. Anal. Biochem. 41, 510-516.

5. Giménez, B., Alemán, A., Montero, P., and Gómez-Guillén, M. C. (2009) Antioxidant and functional properties of gelatin hydrolysates obtained from skin of sole and squid. Food Chem. 114, 976-983.

6. Gómez-Guillén, M. C., Giménez, B., López-Caballero, M. E., and Montero, M. P. (2011) Functional and bioactive properties of collagen and gelatin from alternative sources: A review. Food Hydrocolloid 25, 1813-1827.

7. Gu, R. Z., Li, C. Y., Liu, W. Y., Yi, W. X., and Cai, M. Y. (2011) Angiotensin I-converting enzyme inhibitory activity of low-molecular-weight peptides from Atlantic salmon (Salmosalar L.) skin. Food Res. Int. 44, 1536-1540.

8. Iwai, K., Hasegawa, T., Taguchi, Y., Morimatsu, F., Sato, K., 
Nakamura, Y., Higashi, A., Kido, Y., Nakabo, Y., and Ohtsuki, K. (2005) Identification of food-derived collagen peptides in human blood after oral ingestion of gelatin hydrolysates. J. Agric. Food Chem. 53, 6531-6536.

9. Johnston, N., Dettmar, P. W., Bishwokarma, B., Lively, M. O., and Kouffman, J. A. (2001) Activity/stability of human pepsin: implications for reflux attributed laryngeal disease. Laryngoscope 117, 1036-1039.

10. Laemmli, U. K. (1970) Cleavage of structural proteins during assembly of head of bacteriophage T4. Nature 227, 680685.

11. Lee, M. Y., Choi, Y. C., Chun, J. Y., Min, S. G., and Hong, G. P. (2013) Effects of high pressure/high temperature processing on the recovery and characteristics of porcine placenta hydrolysayes. Korean J. Food Sci. An. 33, 474-480.

12. Nelson,D. R. and Cox, M. M. (2008) Lehninger principles of biochemistry. 5th ed, W. H. Freeman, San Francisco, pp. 183-234.

13. Northrop, D. B. (2002) Effects of high pressure on enzymatic activity. Biochim.Biophys.Acta. 1595, 71-79.

14. Peñas, E., Préstamo, G., Baeza, M. L., Martínez-Molero, M. I., and Gomez, R. (2006) Effects of combined high pressure and enzymatic treatments on the hydrolysis and immunoreactivity of dairy whey proteins. Int. Dairy J. 16, 831-839.
15. Peñas, E., Préstamo, G., and Gomez, R. (2004) High pressure and the enzymatic hydrolysis of soybean whey proteins. Food Chem. 85, 641-648.

16. Rodriguez, J., Gupta, N., Smith, R. D., and Pevzner, P. A. (2008) Does trypsin cut before proline? J. Proteome. 7, 300305.

17. Ruan, K., Lange, R., Bec, N., and Balny, C. (1997) A stable partly denatured state of trypsin induced by high hydrostatic pressure. Biochem. Biophys. Res. Commun. 239, 150-154.

18. Skierka, E. and Safdowska, M. (2007) The influence of different acids and pepsin on the extractability of collagen from the skin of Baltic cod (Gadusmorhua). Food Chem. 105, 1302-1306.

19. Suzuki, A., Watanabe, M., and Ikeuchi, Y. (1993) Effects of high-pressure treatment on the ultrastructure and thermal behavior of beef intramuscular collagen. Meat Sci. 35, 17-25.

20. Szpak, P. (2011) Fish bone chemistry and ultrastructure: implications for taphonomy and stable isotope analysis. $J$. Archaeol. Sci. 38, 3358-3372.

21. Tsugita, A. and Scheffler, J. J. (1982) A rapid method for acid hydrolysis of protein with a mixture of trifluoroacetic acid and hydrochloric acid. Eur. J.Biochem. 124, 585-588.

$\overline{\text { (Received 2013.11.25/Revised 2013.12.27/Accepted 2013.12.27) }}$ 